NASA/TM-2012-217640

\title{
Advanced Stirling Radioisotope Generator (ASRG) Thermal Power Model in MATLAB ${ }^{\circledR}$
}

Xiao-Yen J. Wang

Glenn Research Center, Cleveland, Ohio 


\section{NASA STI Program . . . in Profile}

Since its founding, NASA has been dedicated to the advancement of aeronautics and space science. The NASA Scientific and Technical Information (STI) program plays a key part in helping NASA maintain this important role.

The NASA STI Program operates under the auspices of the Agency Chief Information Officer. It collects, organizes, provides for archiving, and disseminates NASA's STI. The NASA STI program provides access to the NASA Aeronautics and Space Database and its public interface, the NASA Technical Reports Server, thus providing one of the largest collections of aeronautical and space science STI in the world. Results are published in both non-NASA channels and by NASA in the NASA STI Report Series, which includes the following report types:

- TECHNICAL PUBLICATION. Reports of completed research or a major significant phase of research that present the results of NASA programs and include extensive data or theoretical analysis. Includes compilations of significant scientific and technical data and information deemed to be of continuing reference value. NASA counterpart of peer-reviewed formal professional papers but has less stringent limitations on manuscript length and extent of graphic presentations.

- TECHNICAL MEMORANDUM. Scientific and technical findings that are preliminary or of specialized interest, e.g., quick release reports, working papers, and bibliographies that contain minimal annotation. Does not contain extensive analysis.

- CONTRACTOR REPORT. Scientific and technical findings by NASA-sponsored contractors and grantees.
- CONFERENCE PUBLICATION. Collected papers from scientific and technical conferences, symposia, seminars, or other meetings sponsored or cosponsored by NASA.

- SPECIAL PUBLICATION. Scientific, technical, or historical information from NASA programs, projects, and missions, often concerned with subjects having substantial public interest.

- TECHNICAL TRANSLATION. Englishlanguage translations of foreign scientific and technical material pertinent to NASA's mission.

Specialized services also include creating custom thesauri, building customized databases, organizing and publishing research results.

For more information about the NASA STI program, see the following:

- Access the NASA STI program home page at http://www.sti.nasa.gov

- E-mail your question to help@sti.nasa.gov

- Fax your question to the NASA STI Information Desk at 443-757-5803

- Phone the NASA STI Information Desk at 443-757-5802

- Write to: STI Information Desk NASA Center for AeroSpace Information 7115 Standard Drive Hanover, MD 21076-1320 
NASA/TM-2012-217640

\section{Advanced Stirling Radioisotope Generator (ASRG) Thermal Power Model in MATLAB ${ }^{\circledR}$}

Xiao-Yen J. Wang

Glenn Research Center, Cleveland, Ohio

Prepared for the

9th International Energy Conversion Engineering Conference (IECEC)

sponsored by the American Institute of Aeronautics and Astronautics

San Diego, California, July 31-August 3, 2011

National Aeronautics and

Space Administration

Glenn Research Center

Cleveland, Ohio 44135 


\section{Acknowledgments}

The author thanks Paul Schmitz, Edward Lewandowski, Scott Wilson, Jeffrey Schreiber, Stacey Bagg, and Robert Cataldo at NASA GRC for providing critical data and technical discussions for this modeling effort; Dave Meer, Robert Christie, Daniel

Houser, Robert Cataldo for reviewing this paper; Christopher Steffen, Duane Beach, and Craig Williams at NASA Glenn Research Center for supporting this effort under the radioisotope power system (RPS) program.

This report contains preliminary findings, subject to revision as analysis proceeds.

Trade names and trademarks are used in this report for identification only. Their usage does not constitute an official endorsement, either expressed or implied, by the National Aeronautics and Space Administration.

Level of Review: This material has been technically reviewed by technical management.

Available from

NASA Center for Aerospace Information 7115 Standard Drive

Hanover, MD 21076-1320
National Technical Information Service 5301 Shawnee Road Alexandria, VA 22312 


\title{
Advanced Stirling Radioisotope Generator (ASRG) Thermal Power Model in MATLAB ${ }^{\circledR}$
}

\author{
Xiao-Yen J. Wang \\ National Aeronautics and Space Administration \\ Glenn Research Center \\ Cleveland, Ohio 44135
}

\begin{abstract}
This paper presents a one-dimensional steady-state mathematical thermal power model of the ASRG. It aims to provide a guideline of understanding how the ASRG works and what can change its performance. The thermal dynamics and energy balance of the generator is explained using the thermal circuit of the ASRG. The Stirling convertor performance map is used to represent the convertor. How the convertor performance map is coupled in the thermal circuit is explained. The ASRG performance characteristics under i) different sink temperatures and ii) over the years of mission (YOM) are predicted using the one-dimensional model. Two Stirling converter control strategies, i) fixing the hot-end of temperature of the convertor by adjusting piston amplitude and ii) fixing the piston amplitude, were tested in the model. Numerical results show that the first control strategy can result in a higher system efficiency than the second control strategy when the ambient gets warmer or the general-purpose heat source (GPHS) fuel load decays over the YOM. The ASRG performance data presented in this paper doesn't pertain to the ASRG flight unit. Some data of the ASRG engineering unit (EU) and flight unit that are available in public domain are used in this paper for the purpose of numerical studies.
\end{abstract}

\subsection{Introduction}

The advanced Stirling radioisotope generator (ASRG) (Refs. 1 to 3 ) is being developed for multimission applications to provide a high-efficiency power source alternative to radioisotope thermoelectric generators (RTGs). The ASRG efficiency could reach 28 to 32 percent, which results in reducing the required amount of radioisotope by roughly a factor of 4 compared to RTGs. Thus, because of the limited supply of $\mathrm{Pu}-238$, utilization of the ASRG can extend radioisotope power available for future space science missions, such as deep-space missions, large planetary surface rovers, and systems in support of human exploration activities.

An overview of the ASRG is shown in Figure 1. The ASRG consists of two advanced Stirling convertors (ASCs) enclosed in the housing; each has a general purpose heat source (GPHS) attached at the hot end to provide the heat. A gas management valve (GMV) and pressure relief device (PRD) are located at the top of the housing. The housing with attached fins radiates the heat to the environment. The GMV is used to maintain a near-atmosphere pressure of inert gas inside the housing during ground operations. This gas is permanently vented to vacuum by the PRD when the ambient becomes vacuum. The ASC control unit (ACU) is separate from the ASRG housing. It converts the AC signals from both ASC to 28 to 34 VDC for a typical spacecraft electrical bus. The controller is used to maintain synchronized displacer/piston movement of the two directionally opposed Stirling convertors to minimize induced disturbance to the spacecraft and its precision instrumentation.

An ASC consists of a free-piston Stirling converter and an integral linear alternator that converts the piston reciprocating motion to electrical power output. The Stirling engine is a heat engine that operates by cyclic compression and expansion of a working fluid at different temperature levels such that there is net conversion of heat energy to mechanical work. The GPHS provides the heat to the heater head of the ASC. Helium is used as the working fluid that is hermetically contained within the converter pressure vessel and is in the various working stages of the ASC. The displacer shuttles helium between the expansion space, where heat is received, and the compression space, where the heat is rejected at the cold 


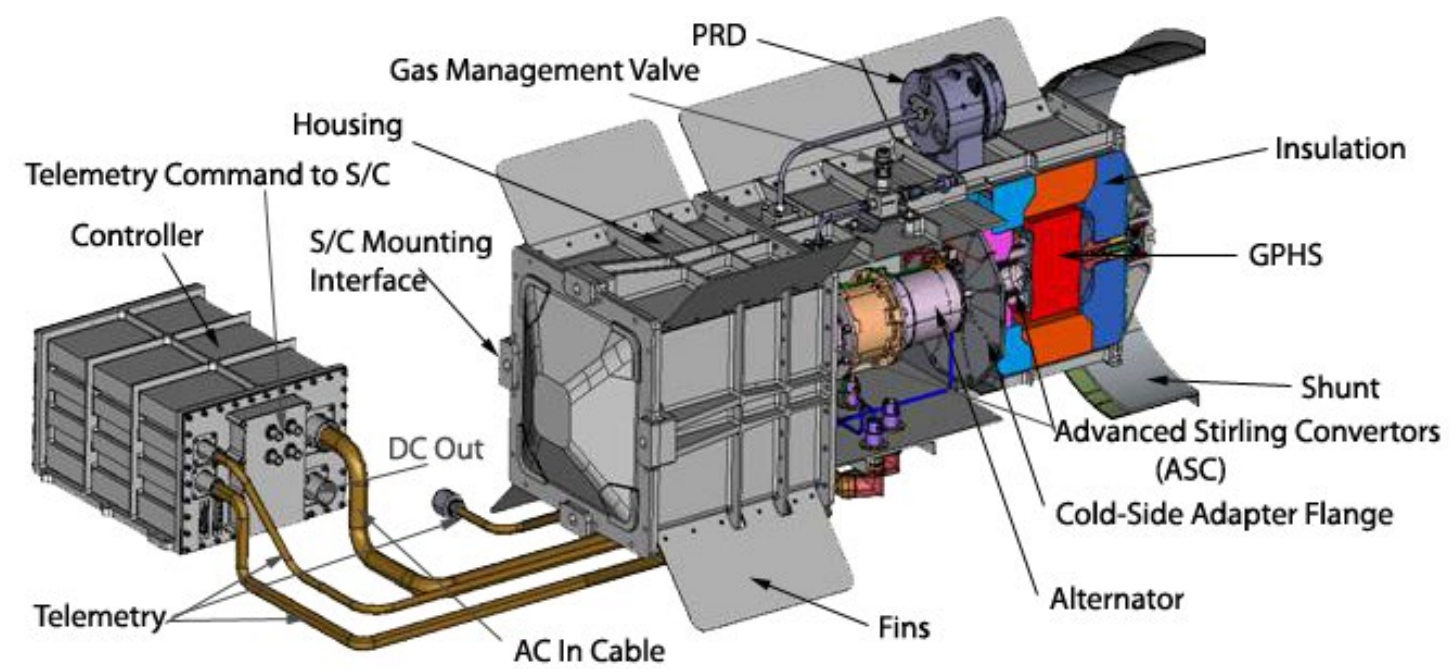

Figure 1.-Overview of the ASRG components

side adapter flange (CSAF) attached to the housing. The changes in pressures and volumes of the convertor working spaces drives a power piston that reciprocates to produce $\mathrm{AC}$ electrical power via a permanent magnet linear alternator.

The ASRG DC power output depends on the following:

1) GPHS fuel load at the year of mission (YOM)

2) Thermal insulation loss from GPHS to the environment

3) ASC efficiency (i.e., Stirling engine efficiency $\times$ alternator efficiency, the ratio of the AC power output and heat going into the engine)

4) Cable/connector power loss

5) ACU power loss

In this paper, a one-dimensional steady-state thermal power model is built to predict the ASRG AC power output. The ASC is modeled using the Sage performance map (Ref. 4) that provides the ASC efficiency. With given GPHS fuel load and defined ambient conditions, the AC power output is computed using the one-dimensional model. Assuming the cable/connector power loss is 0.8 percent of the AC power and the ACU efficiency is 87 percent, the ASRG DC power can be computed and will be presented in the paper.

In the following, the ASRG thermodynamics and energy balance will be explained first, then ASRG performance under varying ambient sink temperature (for different missions) and over the year of mission (for GPHS decay) are shown using two ASC control strategies: (i) fixing the hot-end temperature of the ASC and (ii) fixing the piston amplitude; which is followed by the summary and conclusions.

\subsection{Thermal Dynamics and Energy Balance of the ASRG}

\subsection{The Fundamentals of the Idealized Stirling Cycle}

The idealized Stirling cycle is a Carnot cycle (see Figure 2) with four thermodynamic processes acting on the working fluid:

1) Isothermal expansion at the hot-end temperature of the $\mathrm{ASC}, T_{h}$

2) Constant-volume heat removal

3) Isothermal compression at the cold-end temperature of the ASC, $T_{c}$

4) Constant-volume heat addition. 




Figure 2.-P-V diagram of the Carnot cycle

The heat going into the engine, $Q_{i n}$, is the area of $A B F E$. The heat rejected from the engine, $Q_{r e j}$, is the area of $C D E F$. The mechanical work, $W\left(=Q_{i n}-Q_{r e j}\right)$, is the area of $A B C D$. The net power output, $P=W$ $f$ with $f$ being the frequency of the Stirling engine. It was shown in (Ref. 5) (Eq. (14)) with $K=0, T_{h}=T_{3}$, $Q_{\text {in }}=Q_{3-4}$, Equation (10) with $K=0, T_{c}=T_{1}, Q_{r e j}=-Q_{1-2}$ ), we can have

$$
\begin{gathered}
Q_{i n}=m R \ln \frac{V_{D}+V_{P}}{V_{D}} T_{h} \\
Q_{r e j}=m R \ln \frac{V_{D}+V_{P}}{V_{D}} T_{c}
\end{gathered}
$$

and

$$
P=\left(Q_{i n}-Q_{r e j}\right) f=f m R \ln \frac{V_{D}+V_{P}}{V_{D}}\left(T_{h}-T_{c}\right)
$$

where $V_{D}$ is displacer swept volume, $V_{P}$ is the piston swept volume, $m$ is the mass of the working fluid, and $R$ is the gas constant. From Equations (1) and (2), then we can have the resistances at the hot and cold ends, respectively, of an idealized Stirling engine defined as

$$
\begin{gathered}
R_{6_{-} h}^{i}=\frac{T_{h}}{Q_{i n}}=\frac{1}{f m R \ln \frac{V_{D}+V_{P}}{V_{D}}} \\
R_{6_{-} c}^{i}=\frac{T_{c}}{Q_{r e j}}=\frac{1}{f m R \ln \frac{V_{D}+V_{P}}{V_{D}}}
\end{gathered}
$$

However, in practice, it is difficult to determine $V_{D}$ and $V_{P}$. Some uncertainties of the Stirling engine performance such as regenerator effectiveness, dead volumes, and other losses have to be considered. The shaded area inside $A B C D$ in Figure 2 represents the actual work done by the converter. West (Ref. 6) gave an engineering model to compute the power output of a Stirling engine as follows:

$$
P=w_{n} \frac{f V_{P} p_{m}}{T_{h}+T_{c}}\left(T_{h}-T_{c}\right)
$$

where $p_{m}$ is effective mean pressure of the Stirling engine and $w_{n}$ is West number for the Stirling engine, in the range of 0.25 to 0.35 .

Following Equations (4) and (5), we can define the resistance based on the West equation as follows: 


$$
R_{6_{-} h}^{w}=R_{6 \_c}^{w}=\frac{1}{w_{n} \frac{f V_{p} p_{m}}{T_{h}+T_{c}}}
$$

It can be seen that the resistance at both the hot and cold ends are the functions of the Stirling engine frequency, piston swept volume (piston amplitude), effective mean pressure, $T_{h}$, and $T_{c}$. When the piston amplitude decreases, the resistance will increase. The resistances at the hot and cold ends are the same based on equations for an idealized Stirling engine or West equation. However, in reality, the resistance at the hot and cold ends of the engine could be different due to the losses in the engine are counted in different ways at the hot and cold ends, which is shown in the Sage performance map (Ref. 4).

\subsection{Thermal Circuit of the ASRG}

The thermal circuit for half of the ASRG is shown in Figure 3, where $T_{s}$ is the temperature of the GPHS, $T_{h}$ is the temperature at the hot end of the ASC, $T_{c}$ is the temperature at the cold end of the ASC, $T_{w}$ is the housing wall temperature and $T_{a}$ is the equivalent ambient sink temperature. $R_{1}$ is the contact and conduction resistances between GPHS and housing wall; $R_{2}$ is the contact and conduction resistances between GPHS and heat collector of the ASC; $R_{3}$ is the contact and conduction resistances between the ASC hot end and housing wall; $R_{4}$ is the conduction resistance between the cold end of the ASC and housing wall; $R_{4}^{\prime}$ is the convection and/or radiation resistances between housing wall and the ambient environment; $R_{5}$ is the conduction resistance between the hot and cold ends of the ASC; $R_{6 \_} h$ is the resistance of the ASC at the hot end. The convertor acts like a thermal resistance in the thermal perspective.

With $Q_{\text {total }}$ and $T_{a}$ being defined and imposed as boundary conditions, the total heat $Q_{\text {total }}$ provided from the GPHS will split into $Q_{\text {loss } 1}\left(\right.$ loss through the thermal insulation around the GPHS) and $Q_{\text {in }}$ to the ASC. The heat going into the ASC further splits into three paths: $Q_{\text {loss_2 }}$ (loss through conduction), $Q_{\text {loss } 3}$ (loss through insulation), and $Q_{\text {work }}$ ( heating up the gas to do the work). $Q_{r e j}$ is the heat rejected from the ASC through the CSAF attached to the housing. All the waste heat will be rejected to the ambient through radiation and/or convection. How the heat splits depends on the thermal resistances in the circuit, such as $R_{1}, R_{2}, R_{3}, R_{4}, R_{5}, R_{4}^{\prime}$ and $R_{6 \_}$(see Figure 3). $R_{6 \_}$and $Q_{r e j}$ are functions of $T_{h}, T_{c}, Q_{i n}, Q_{r e j}$, and $A_{p}$ (piston amplitude). $R_{1}, R_{2}, R_{3}, R_{4}, R_{5}, R_{4}^{\prime}$ can be defined based on the material properties and the condition of contact surfaces. $R_{6 \_}$and $Q_{r e j}$ will be defined based on the ASC performance map (Ref. 4). $T_{b}$ is a boundary node used to define $R_{6 \_}$between $T_{h}$ and $T_{b .} Q_{\text {rej }}$ is imposed as a heat load at a boundary node that has temperautre of $T_{c \text {. }}$ An iterative procedure has to be used to get the correct $R_{6 \_h}$ and $Q_{\text {rej }}$ that satisfy both the energy balance of the ASRG thermal circuit and the ASC performance map. The three steps in the iterative procedure are listed as follows; (i) give initial values of $R_{6 \_}$and $Q_{\text {rej; }}$; (ii) run the thermal model to compute temperatures and heat flows, such as $T_{h}, T_{c}$, and $Q_{i n \text {; }}$ (iii) use $T_{h}, T_{c}$, and $Q_{i n}$ to update the $R_{6 \_} h$ and $Q_{r e j}$ based on the ASC performance map; The three steps are repeated until the differences of $R_{6 \_} h$ and $Q_{r e j}$ between two iterations are small enough $\left(10^{-4}\right)$ to conclude that the solution is converged.

Note that housing temperature can be quite different on the housing and the convective heat transfer could vary significantly around housing when it exists. Here, the variation of the housing temperature is not considered. It is assumed that only radiation exists in the following ASRG performance prediction.

In the following, the relationship between $Q_{i n}, T_{h}$ and $R_{6-h}$ (i.e., $A_{p}$ ), $T_{a}$ at the hot end will be derived first, which is followed by the relationship between $Q_{r e j}, T_{c}$ and $R_{6_{-} c}$ (i.e., $A_{p}$ ), $T_{a}$ at the cold end. Assuming $Q_{\text {in }}=Q_{\text {work }}$ to simplify the derivation, we have

$$
\begin{gathered}
Q_{\text {total }}=Q_{\text {loss_1 }_{-}}+Q_{i n} \\
Q_{\text {loss_1 }}=\frac{T_{s}-T_{w}}{R_{1}}
\end{gathered}
$$




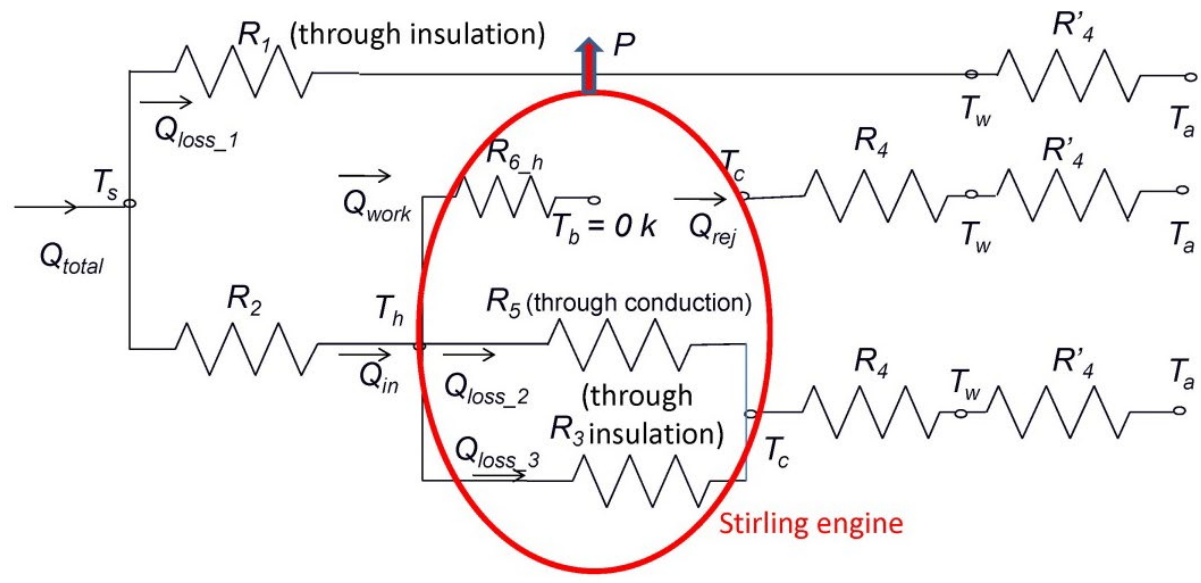

Figure 3.-Thermal circuit for half of the ASRG

$$
\begin{gathered}
Q_{i n}=\frac{T_{s}-T_{h}}{R_{2}} \\
Q_{i n}=\frac{T_{h}}{R_{6 \_} h}
\end{gathered}
$$

Equations (10) and (11) give

$$
\begin{gathered}
T_{s}=Q_{i n} R_{2}+T_{h} \\
T_{h}=Q_{\text {in }} R_{6 \_} h
\end{gathered}
$$

Substituting Equations (12) and (13) into Equation (9), we will get

$$
Q_{\text {loss_ } 1}=\frac{\left(R_{2}+R_{6 \_} h\right) Q_{i n}-T_{w}}{R_{1}}
$$

By substituting Equation (14) into Equation (8), we will get

$$
Q_{i n}=\frac{Q_{\text {total }}+\frac{T_{w}}{R_{1}}}{1+\frac{R_{2}+R_{6 \_} h}{R_{1}}}
$$

Then substitute Equation (15) into Equation (13), and we get

$$
T_{h}=\frac{Q_{\text {total }}+\frac{T_{w}}{R_{1}}}{\frac{1+R_{2} / R_{1}}{R_{6 \_} h}+\frac{1}{R_{1}}}
$$

It can be seen that if $T_{w}$ increases (i.e., $T_{a}$ increases), $T_{h}$ and $Q_{\text {in }}$ will increase and $Q_{\text {loss }} 1$ will decrease. If $R_{6 \_}$is increases, $T_{h}$ will increase, $Q_{i n}$ will drop, thus $Q_{\text {loss } \_1}$ will increase.

At the cold end of the ASC, we have 


$$
\begin{gathered}
Q_{r e j}=A_{1} \varepsilon \sigma\left(T_{w}^{4}-T_{a}^{4}\right)+h A_{2}\left(T_{w}-T_{a}\right)=\frac{T_{w}-T_{a}}{R_{4}^{\prime}} \\
Q_{r e j}=\frac{T_{c}-T_{w}}{R_{4}} \\
Q_{r e j}=\frac{T_{c}}{R_{6_{-} c}}
\end{gathered}
$$

where $A_{1}$ is the housing area, $A_{2}$ is the convective heat transfer area, $\varepsilon$ is the surface emissivity, $\sigma$ is the Stefan-Boltzmann constant, and $h$ is the convection heat transfer coefficient. Equations (17) and (18) give

$$
\begin{aligned}
& T_{w}=T_{a}+R_{4}^{\prime} Q_{r e j} \\
& T_{w}=T_{c}-R_{4} Q_{r e j}
\end{aligned}
$$

By combining Equations (19), (20), and (21), we get

$$
\begin{gathered}
T_{c}=\frac{T_{a}}{1-\frac{R_{4}+R_{4}^{\prime}}{R_{6 \_} c}} \\
T_{w}=\frac{T_{a}}{1-\frac{R_{4}^{\prime}}{R_{6 \_}-R_{4}}}
\end{gathered}
$$

It can been seen that when $T_{a}$ increases, $T_{c}$ and $Q_{r e j}$ will increase. When $R_{6 \_c}$ increases, $T_{c}$ and $Q_{r e j}$ will decrease.

In summary,

1) If the piston amplitude decreases,

o $\quad R_{6 \_}$and $R_{6 \_c}$ increase, then

o $T_{h}$ increases; Equation (16)

o $Q_{\text {in }}$ drops; Equation (15)

o $T_{c}$ drops; Equation (22)

o $Q_{\text {rej }}$ drops; Equation (19)

0 the net power output $(P)$ drops.

2) If the sink temperature increases,

o $T_{h}$ increases; Equation (16)

o $Q_{\text {in }}$ increases; Equation (15)

o $T_{c}$ increases; Equation (22)

o $Q_{\text {rej }}$ increases; Equation (19)

0 the net power output $(P)$ drops.

\subsection{One-Dimensional Thermal Power Model Results}

The one-dimensional thermal model described above is built in Matlab and used to predict the ASRG performance using two ASC control strategies. In the following, the ASRG performance characteristics under YOM is described first, which is followed by the corresponding performance under different ambient sink temperature. 


\section{1 $\quad$ ASRG Performance Characteristic Under YOM}

The ASRG power output is studied for the YOM since the GPHS fuel decays with time. A 17-year time frame that includes up to 3-year storage and 14-year on mission is considered, and the fuel decay rate is computed as

$$
\text { YOM GPHS fuel load }=\text { BOM fuel load } \times 0.5^{\text {YOM/87.74 }}
$$

The begining of mission (BOM) fuel load is 244,250 , and $256 \mathrm{~W}$ for minimum, nominal, and maximum cases, respectively. As shown in Figure 4, for BOM fuel load $=244 \mathrm{~W}$, each GPHS fuel load drops $1.8 \mathrm{~W}$ per year and has a 30.6-W total drop at the end of mission $(\mathrm{EOM})$. For BOM fuel load $=256 \mathrm{~W}$, each GPHS has a 32.0-W total drop at the EOM. The fuel almost drops linearly with time.

With the fuel decaying over the YOM, the ASRG power output in deep space (no sun, $T_{a}=4 \mathrm{~K}$ ) is shown in Figure 5(a) using the first ASC control strategy(fixed $T_{h}$ ). It can be seen that ASRG DC power output drops $19 \mathrm{~W}$ within the 17 -year period; that is, a 1.12-We drop per year. $Q_{\text {in }}$ and $Q_{\text {rej }}$ are decreasing since the total heat is decreasing as shown in Figure 5(b) for one ASC; while $T_{h}$ is maintained as constant as that at the BOM, $T_{c}$ decreases a little as shown in Figure 5(c), which results in a higher ASC efficiency. The piston amplitude at EOM is approximately 91.1 percent of that at the BOM.

For the case of starting from the minimum fuel load at BOM, the ASRG DC power output is $121-\mathrm{We}$ with the ASRG efficiency of 28.4 percent at EOM, compared with a 140 -We DC power output with 28.6 percent ASRG efficiency at BOM in deep space, which is referred as the current best estimation (CBE) ASRG power output in (Ref. 7).

The corresponding ASRG power output with the second ASC control strategy(fixed piston amplitude) is presented in Figure 6, showing ASRG DC power output drops 30.5 We within the 17-year period starting from the minimum fuel load at BOM. $Q_{i n}$ and $T_{h}$ are decreasing with YOM, and $Q_{r e j}$ and $T_{\mathrm{c}}$ remain almost constant. The ASC efficiency drop is more significant; thus power output drops more. At EOM, the ASRG DC power output is $109.5-\mathrm{We}$ with the efficiency of 25.7 percent.

For the case of starting from the maximum fuel load at BOM, the ASRG output power drop is very similar to that starting at the minimum fuel load. Also we can see that the DC power output is decreasing linearly with YOM since the fuel decay is almost linear.

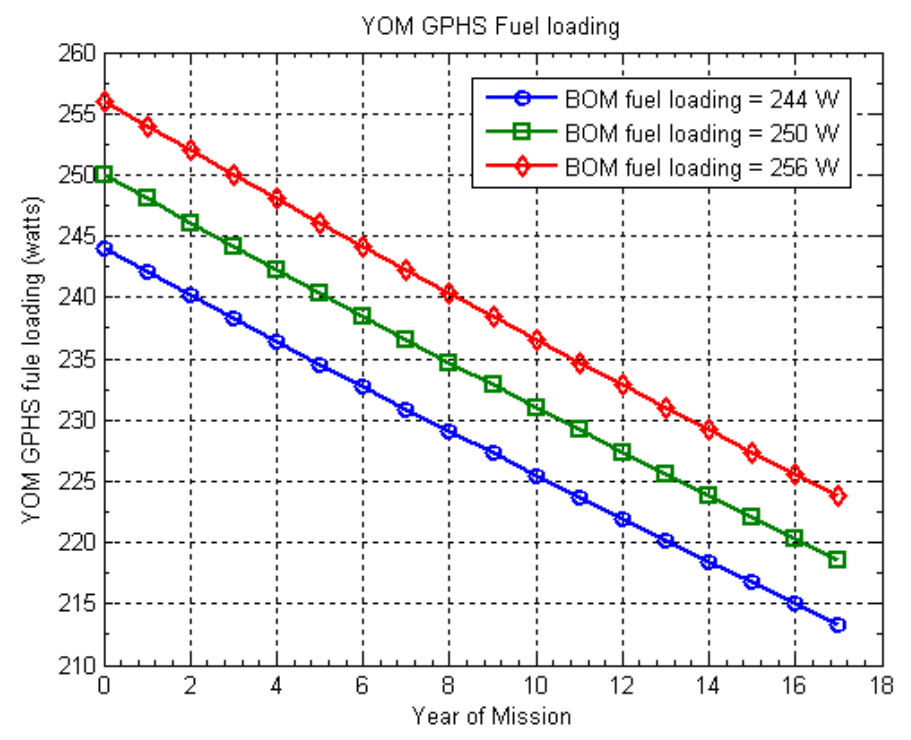

Figure 4.-The GPHS fuel decay under YOM. 


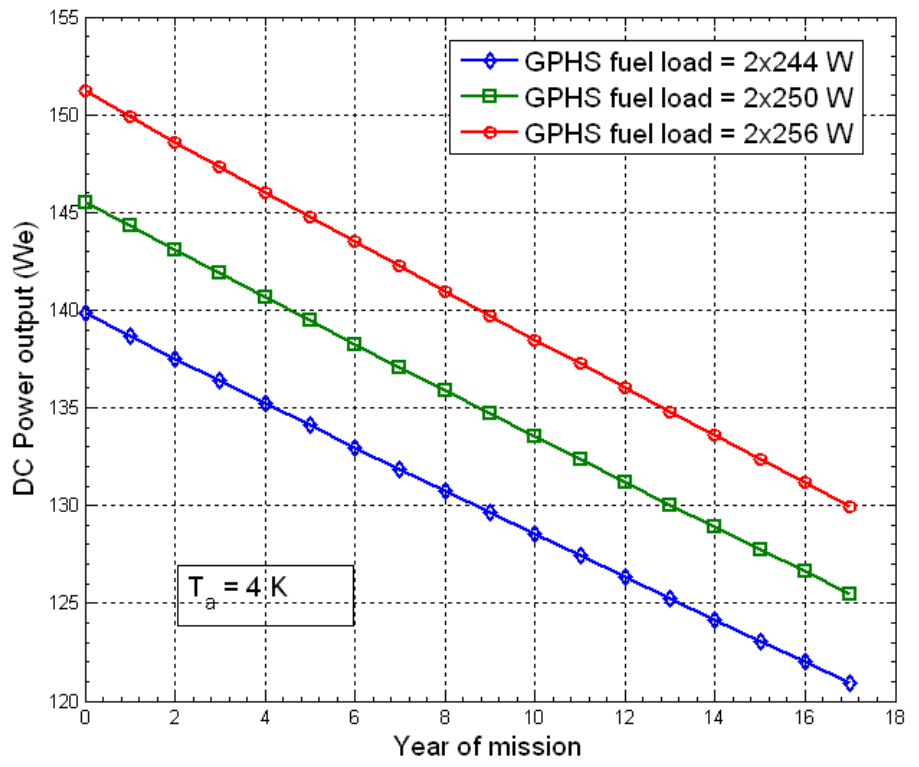

(a)

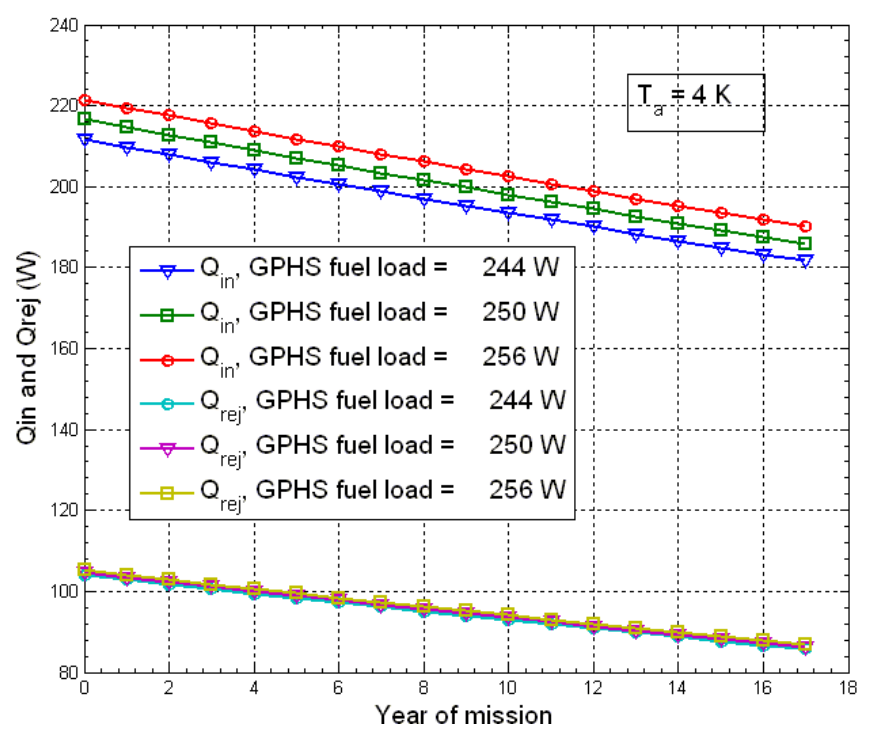

(b)



(c)

Figure 5.-ASRG performance under YOM with fixing $T_{h}$. 


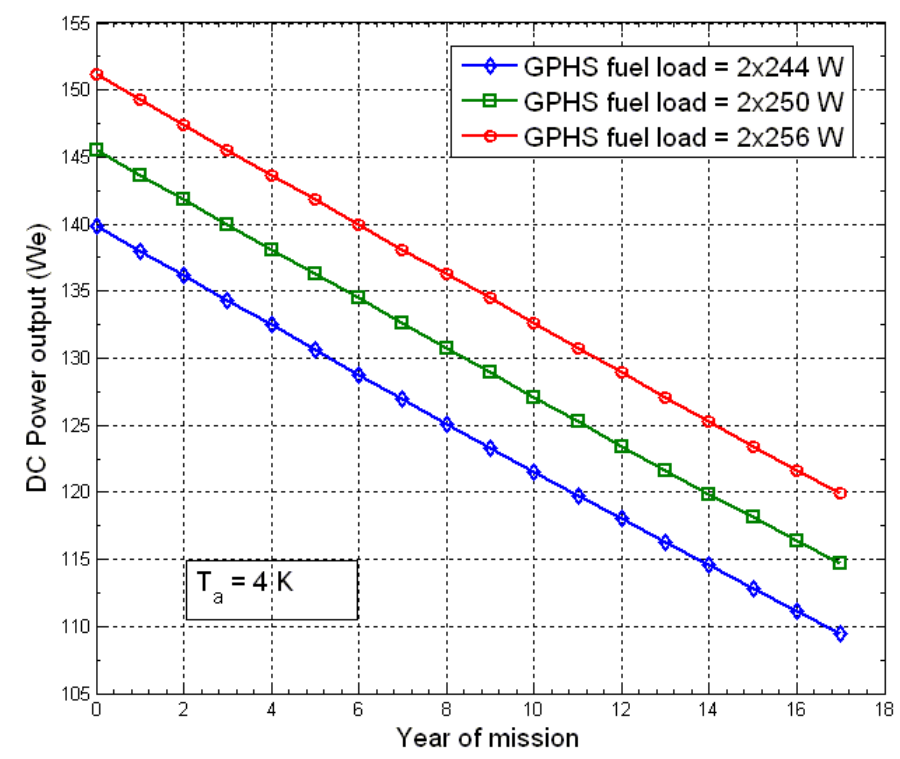

(a)

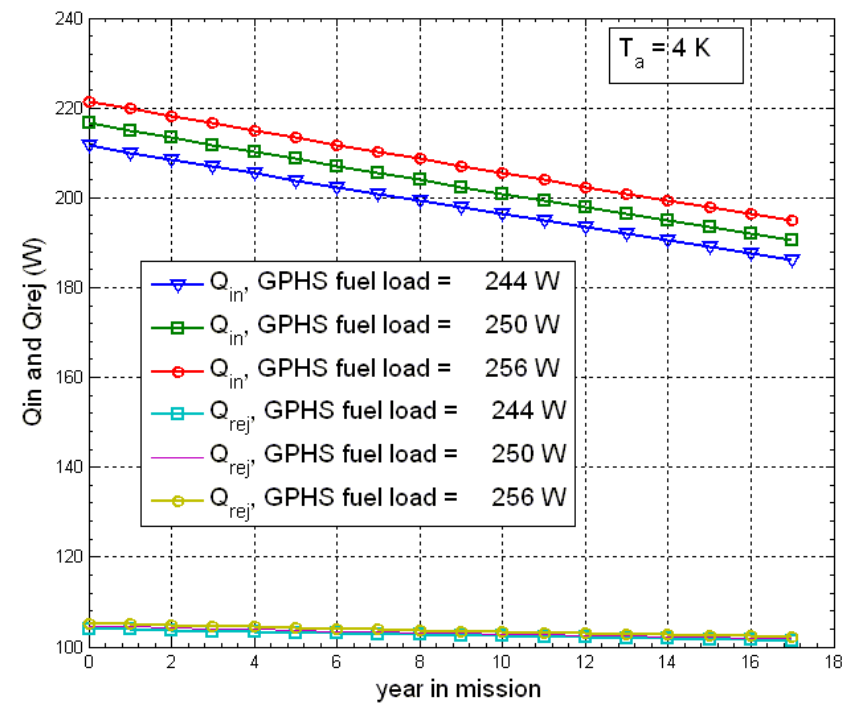

(b)

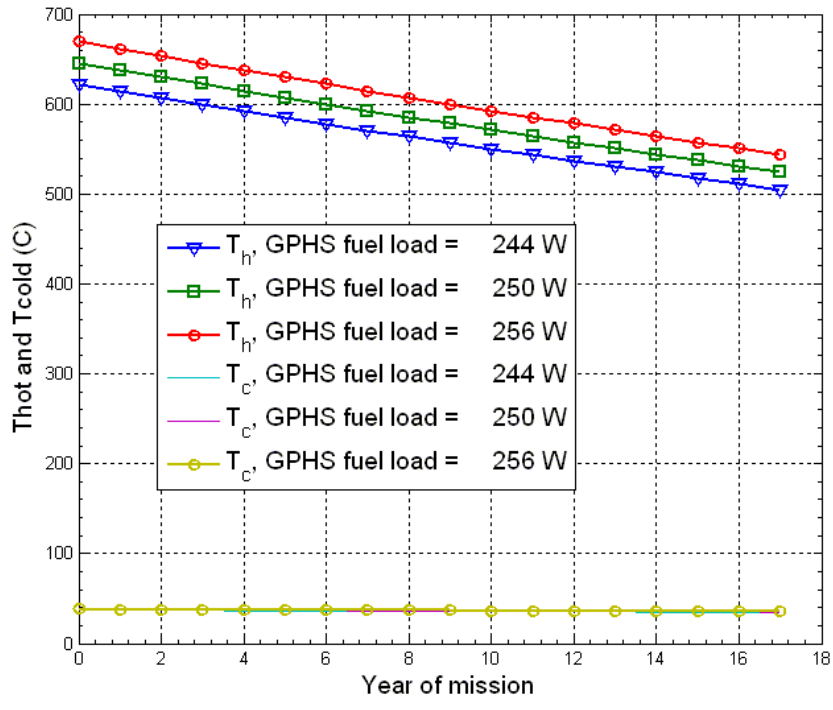

(c)

Figure 6.—ASRG performance under YOM with a fixed piston amplitude.

\subsection{ASRG Performance Characteristic Under Different Ambient Sink Temperature}

For different missions, the environment could be very different. Here, the ambient sink temperature $T_{a}$ varying from 4 to $300 \mathrm{~K}$ as shown in (Ref. 7) is investigated. The equivalent sink temperature of $200 \mathrm{~K}$ is used for the environment on Mars. For a Venus flyby, the sink temperature can be $300 \mathrm{~K}$. It is assumed here that heat only radiates between the ASRG housing and the ambient. The GPHS fuel load is assumed to be 244,250 , and $256 \mathrm{~W}$ for minimum, nominal, and maximam cases at BOM, respectively. The two ASC control strategies are also investigated here.

Figure 7 shows how the ASRG power output varies with the sink temperature for the first ASC control strategy. When the sink temperature gets higher - that is, a warmer environment - $Q_{\text {in }}$ increases a little because insulation loss decreases shown in Figure 7(b) for one ASC. If the $T_{h}$ is fixed, $T_{\mathrm{c}}$ increases 
while $T_{a}$ gets higher as shown in Figure 7(c), which results in a lower ASC efficiency. Thus the power output will drop. For the minimum fuel load case, at $T_{a}=200 \mathrm{~K}$, we can see a $5.2 \mathrm{We}$ power drop from $T_{\mathrm{a}}$ $=4 \mathrm{~K}$, while at $T_{a}=300 \mathrm{~K}$, we can see that $21-\mathrm{We}$ drop and the ASRG efficiency becomes 24.4 percent. In order to maintain $T_{h}$ constant, the piston amplitude at $T_{a}=300 \mathrm{~K}$ becomes 97.8 percent of that at $T_{a}=4 \mathrm{~K}$.

Figure 8 shows the corresponding result using the second ASC control strategy. For the minimum fuel load case, the ASRG DC power output drops $7 \mathrm{We}$ when $T_{a}=200 \mathrm{~K}$, and $27 \mathrm{We}$ drop when $T_{a}=300 \mathrm{~K}$. If the piston amplitude is fixed as a constant, $T_{h}$ drops and $T_{\mathrm{c}}$ increases while $T_{\mathrm{a}}$ gets higher as shown in Figure 8(c), which results in a larger ASC efficiency drop. At $T_{a}=300 \mathrm{~K}$, the ASRG efficiency becomes 23.2 percent.

It shows that the first ASC control strategy can achieve higher ASC efficiency when the ambient gets warmer, thus the power drop becomes less than that when using the second ASC control strategy.

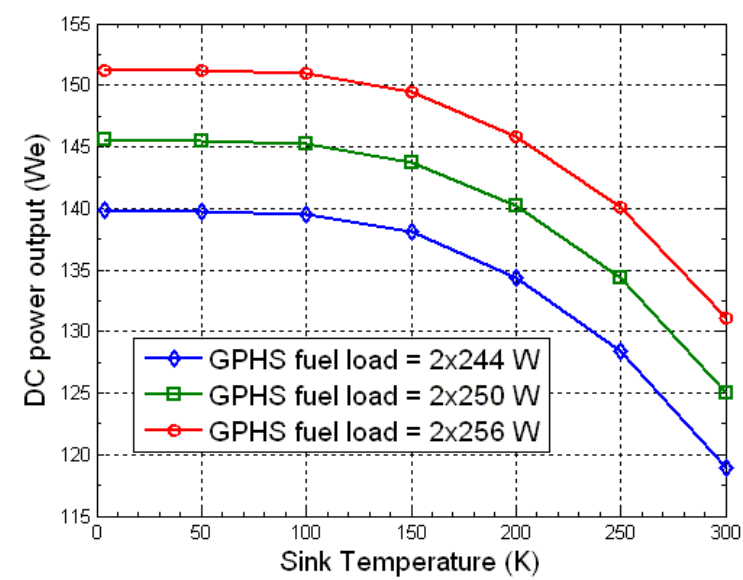

(a)

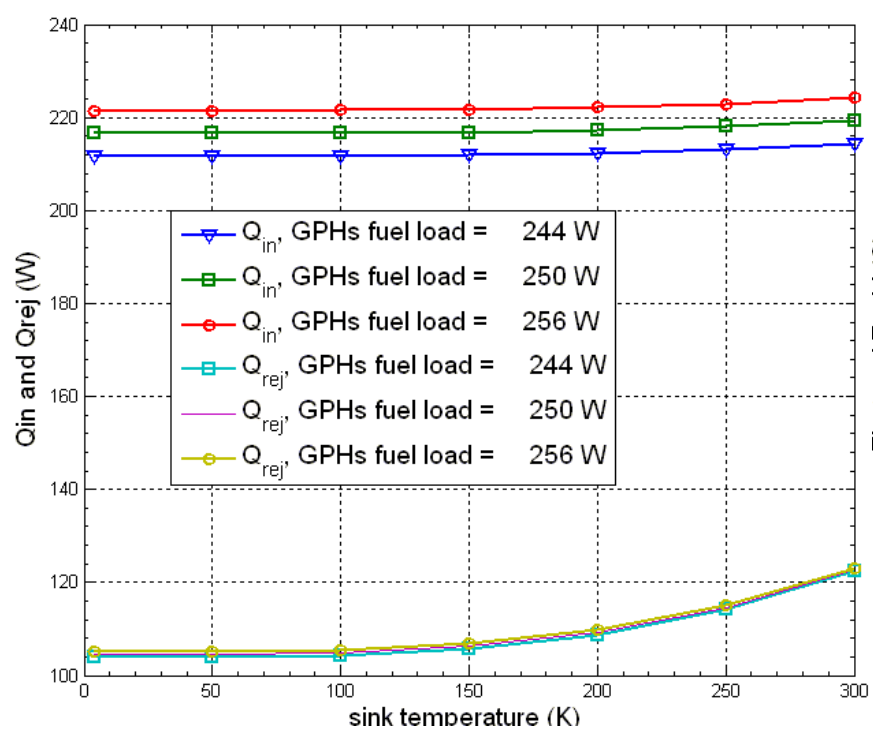

(b)

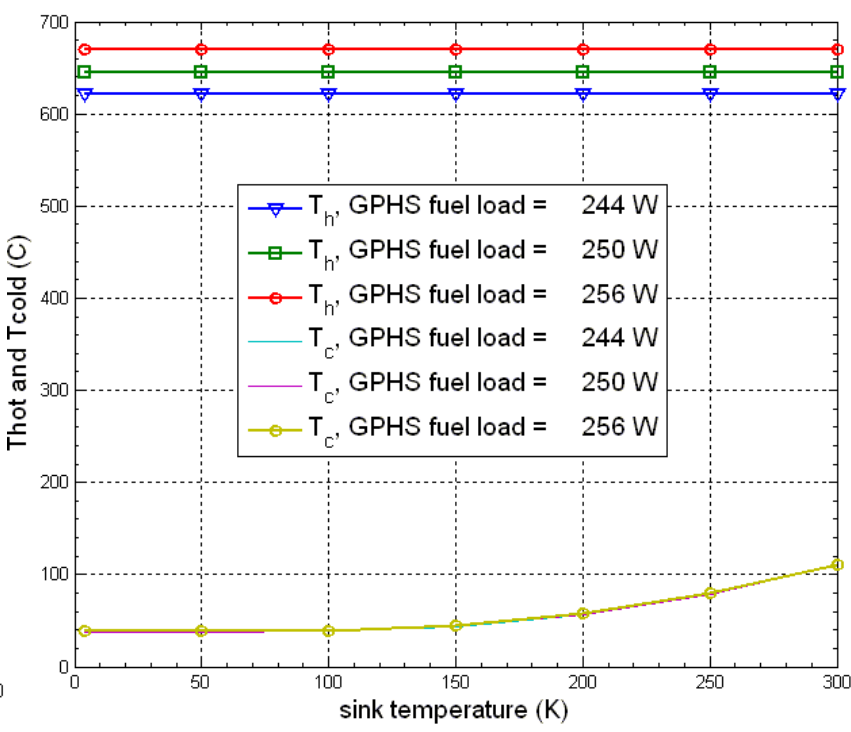

(c)

Figure 7.-ASRG performance under varying sink temperature $T_{a}$ with fixing $T_{h}$. 




(a)

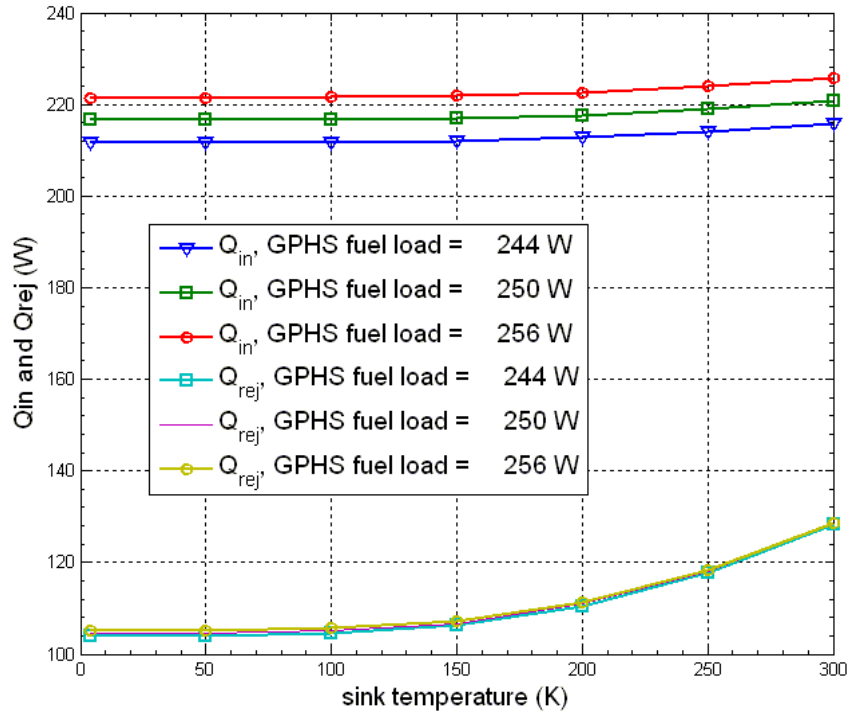

(b)

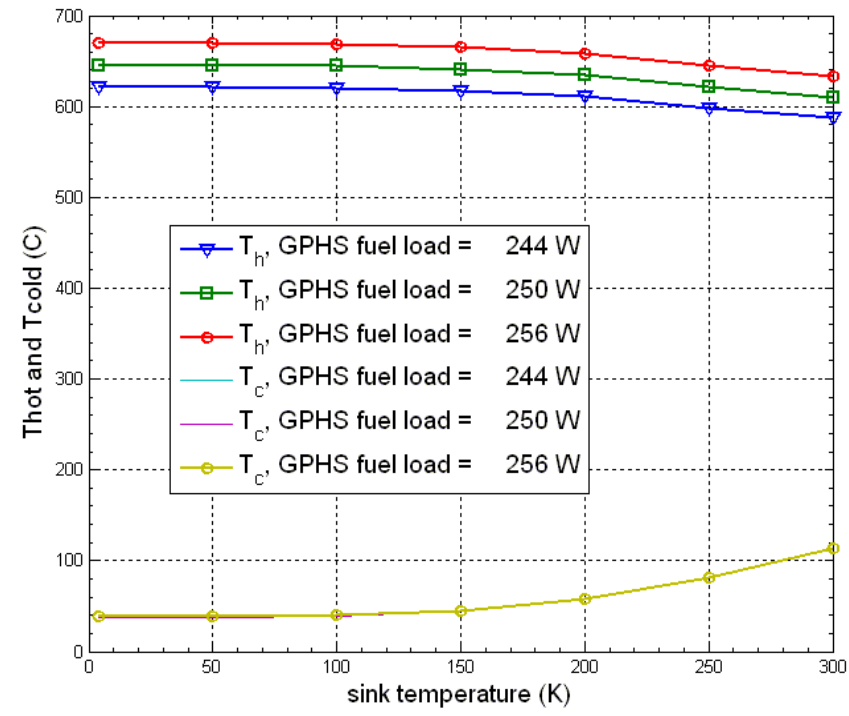

(c)

Figure 8.-ASRG performance under varying sink temperature $T_{a}$ with a fixed piston amplitude.

\subsection{Conclusions}

A one-dimensional steady-state mathematical thermal power model of the ASRG has been presented. How the ASC represented by Sage performance map is coupled in the ASRG thermal circuit has been explained. The ASRG performance characteristics under different environments and GPHS fuel load decay with YOM have been shown. Further validation of the one-dimensional model with a threedimensional finite element ASRG thermal-power model for the flight unit or EU will be performed in future work. 


\section{Appendix-Symbols List}

\begin{tabular}{|c|c|}
\hline$A_{1}$ & housing surface area \\
\hline$A_{2}$ & heat transfer area \\
\hline$A_{p}$ & piston amplitude \\
\hline$f$ & frequency of the Stirling engine \\
\hline$h$ & convection heat transfer coefficient \\
\hline$m$ & mass of the working fluid \\
\hline$P$ & the power output of Stirling engine \\
\hline$p_{m}$ & mean pressure of the ASC \\
\hline$Q_{\text {in }}$ & heat going to the ASC \\
\hline$Q_{\text {loss_1 }} 1$ & heat loss from the GPHS through insulation material to the ambient \\
\hline$Q_{\text {loss_2 }}$ & heat loss from the ASC hot end through insulation material to the ambient \\
\hline$Q_{\text {loss } 3}$ & heat loss through conduction inside the ASC \\
\hline$Q_{r e j}$ & heat rejected from the cold end of the ASC \\
\hline$Q_{\text {total }}$ & total heat generated from the GPHS \\
\hline$Q_{\text {work }}$ & heat going to do the work \\
\hline$R$ & gas constant \\
\hline$R_{1}$ & contact and conduction resistances between GPHS and housing wall \\
\hline$R_{2}$ & contact and conduction resistances between GPHS and heat collector of the ASC \\
\hline$R_{3}$ & contact and conduction resistances between the ASC hot end and housing wall \\
\hline$R_{4}$ & conduction resistance between the cold end of the ASC and housing wall \\
\hline$R_{4}^{\prime}$ & convection and/or radiation resistances between housing wall and the ambient environment \\
\hline$R_{5}$ & conduction resistance between the hot and cold ends of the ASC \\
\hline$R_{6 \_} h$ & resistance at the hot end of the ASC \\
\hline$R_{6 \_} c$ & resistance at the cold end of the ASC \\
\hline$R_{6 \_}^{i} h$ & resistance at the hot end of an idealized Stirling engine \\
\hline$R_{6 \_c}^{i}$ & resistance at the cold end of an idealized Stirling engine \\
\hline$R_{6-h}^{w}$ & resistance at the hot end based on the West equation \\
\hline$R_{6 \_c}^{w}$ & resistance at the cold end based on the West equation \\
\hline$T_{a}$ & equivalent ambient sink temperature \\
\hline$T_{h}$ & temperature at the hot end of the ASC \\
\hline$T_{c}$ & temperature at the cold end of the ASC \\
\hline$T_{s}$ & temperature of the GPHS \\
\hline$T_{w}$ & housing wall temperature \\
\hline$V_{D}$ & displacer swept volume \\
\hline$V_{p}$ & piston swept volume \\
\hline$W$ & the mechanical work from Stirling engine \\
\hline$w_{n}$ & West number \\
\hline$\varepsilon$ & surface emissivity \\
\hline$\sigma$ & Stefan-Boltzmann constant \\
\hline
\end{tabular}




\section{References}

1. J. Chan, J.G. Wood, J.G. Schreiber, "Development of Advanced Stirling Radioisotope Generator for Space Exploration," presented at the Space Technology and Applications International Forum (STAIF), February 11-15, 2007.

2. E.J. Lewandowski, J.G. Schreiber, "Testing to characterize the Advanced Stirling Radioisotope Generator engineering unit," presented at the 8th International Energy Conversion Engineering Conference (IECEC), July 25-28, 2010.

3. T.F. Regan, E.J. Lewandowski, "Development of a Stirling system dynamic model with enhanced thermodynamics," NASA/CR-2005-214018.

4. Sage data of ASC E2, private communication with G. Wood at Sunpower, May 13, 2009.

5. B. Kongtragool, S. Wongwises, "Thermodynamic analysis of a Stirling engine including dead volumes of hot space, cold space and regenerator," Renewable energy, Volume 31, Issue 3, March 2006, pp. 345-359, Pascal Puech, Victoria Tishkova.

6. C.D. West, "Stirling Engines and Irrigation pumping," ORNL/TM-10475, Sep. 8, 1987.

7. ASRG User ICD, 912IC002085, Lockheed Martin, May 2010. 



\begin{tabular}{|c|c|c|}
\hline \multicolumn{2}{|c|}{ REPORT DOCUMENTATION PAGE } & $\begin{array}{l}\text { Form Approved } \\
\text { OMB No. 0704-0188 }\end{array}$ \\
\hline \multicolumn{3}{|c|}{ 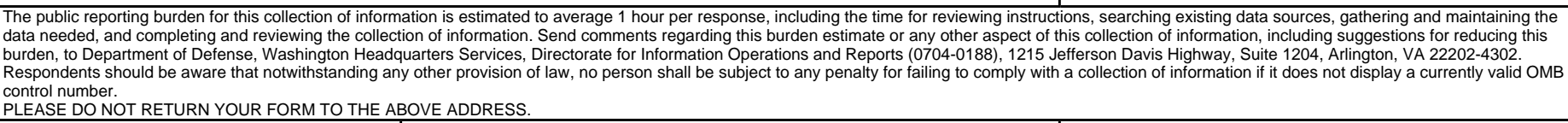 } \\
\hline $\begin{array}{l}\text { 1. REPORT DATE (DD-MM-YYYY) } \\
01-08-2012\end{array}$ & $\begin{array}{l}\text { 2. REPORT TYPE } \\
\text { Technical Memorandum }\end{array}$ & 3. DATES COVERED (From - To) \\
\hline \multirow{3}{*}{\multicolumn{2}{|c|}{$\begin{array}{l}\text { 4. TITLE AND SUBTITLE } \\
\text { Advanced Stirling Radioisotope Generator (ASRG) Thermal Power Model in MATLAB® }\end{array}$}} & 5a. CONTRACT NUMBER \\
\hline & & 5b. GRANT NUMBER \\
\hline & & 5c. PROGRAM ELEMENT NUMBER \\
\hline \multirow{3}{*}{\multicolumn{2}{|c|}{$\begin{array}{l}\text { 6. AUTHOR(S) } \\
\text { Wang, Xiao-Yen, J. }\end{array}$}} & 5d. PROJECT NUMBER \\
\hline & & 5e. TASK NUMBER \\
\hline & & $\begin{array}{l}\text { 5f. WORK UNIT NUMBER } \\
\text { WBS 644423.06.32.01.03 }\end{array}$ \\
\hline \multicolumn{2}{|c|}{$\begin{array}{l}\text { 7. PERFORMING ORGANIZATION NAME(S) AND ADDRESS(ES) } \\
\text { National Aeronautics and Space Administration } \\
\text { John H. Glenn Research Center at Lewis Field } \\
\text { Cleveland, Ohio 44135-3191 }\end{array}$} & $\begin{array}{l}\text { 8. PERFORMING ORGANIZATION } \\
\text { REPORT NUMBER } \\
\text { E-18285 }\end{array}$ \\
\hline \multirow{2}{*}{\multicolumn{2}{|c|}{$\begin{array}{l}\text { 9. SPONSORING/MONITORING AGENCY NAME(S) AND ADDRESS(ES) } \\
\text { National Aeronautics and Space Administration } \\
\text { Washington, DC 20546-0001 }\end{array}$}} & $\begin{array}{l}\text { 10. SPONSORING/MONITOR'S } \\
\text { ACRONYM(S) } \\
\text { NASA }\end{array}$ \\
\hline & & $\begin{array}{l}\text { 11. SPONSORING/MONITORING } \\
\text { REPORT NUMBER } \\
\text { NASA/TM-2012-217640 }\end{array}$ \\
\hline \multicolumn{3}{|c|}{$\begin{array}{l}\text { 12. DISTRIBUTION/AVAILABILITY STATEMENT } \\
\text { Unclassified-Unlimited } \\
\text { Subject Category: } 34 \\
\text { Available electronically at http://www.sti.nasa.gov } \\
\text { This publication is available from the NASA Center for AeroSpace Information, 443-757-5802 }\end{array}$} \\
\hline
\end{tabular}

\section{SUPPLEMENTARY NOTES}

\section{ABSTRACT}

This paper presents a one-dimensional steady-state mathematical thermal power model of the ASRG. It aims to provide a guideline of understanding how the ASRG works and what can change its performance. The thermal dynamics and energy balance of the generator is explained using the thermal circuit of the ASRG. The Stirling convertor performance map is used to represent the convertor. How the convertor performance map is coupled in the thermal circuit is explained. The ASRG performance characteristics under i) different sink temperatures and ii) over the years of mission (YOM) are predicted using the one-dimensional model. Two Stirling converter control strategies, i) fixing the hot-end of temperature of the convertor by adjusting piston amplitude and ii) fixing the piston amplitude, were tested in the model. Numerical results show that the first control strategy can result in a higher system efficiency than the second control strategy when the ambient gets warmer or the general-purpose heat source (GPHS) fuel load decays over the YOM. The ASRG performance data presented in this paper doesn't pertain to the ASRG flight unit. Some data of the ASRG engineering unit (EU) and flight unit that are available in public domain are used in this paper for the purpose of numerical studies.

15. SUBJECT TERMS

Thermal modeling; Stirling radioisotope generator

\begin{tabular}{|c|c|c|c|c|c|}
\hline \multicolumn{3}{|c|}{ 16. SECURITY CLASSIFICATION OF: } & \multirow{2}{*}{$\begin{array}{l}\text { 17. LIMITATION OF } \\
\text { ABSTRACT } \\
\text { UU }\end{array}$} & \multirow{2}{*}{$\begin{array}{l}\text { 18. NUMBER } \\
\text { OF } \\
\text { PAGES } \\
22\end{array}$} & \multirow{2}{*}{$\begin{array}{l}\text { 19a. NAME OF RESPONSIBLE PERSON } \\
\text { STI Help Desk (email:help@sti.nasa.gov) } \\
\text { 19b. TELEPHONE NUMBER (include area code) } \\
\text { 443-757-5802 }\end{array}$} \\
\hline $\begin{array}{l}\text { a. REPORT } \\
U\end{array}$ & $\begin{array}{l}\text { b. ABSTRACT } \\
\mathrm{U}\end{array}$ & $\begin{array}{l}\text { c. THIS } \\
\text { PAGE } \\
\text { U }\end{array}$ & & & \\
\hline
\end{tabular}



